Membrado-Tena, J.C., Hinojosa Sancho, F. M., (2018): Evolución de los usos del suelo en Paterna (Horta de València). De periferia urbana a centro innovador", GeoFocus (Artículos), no 22, p. 141-161. ISSN: 1578-5157

http://dx.doi.org/10.21138/GF.603

\title{
EVOLUCIÓN DE LOS USOS DEL SUELO EN PATERNA (HORTA DE VALÈNCIA). DE PERIFERIA URBANA A CENTRO INNOVADOR
}

\author{
JOAN CARLES MEMBRADO-TENA ${ }^{1}$, FRANCISCO MIGUEL HINOJOSA ${ }^{2}$ \\ SANCHO \\ ${ }^{1}$ Departamento de Geografía. Universitat de València. \\ Av. de Blasco Ibáñez, 28, 46010.Valencia, España \\ joan.membrado@uv.es \\ ${ }^{2}$ Universitat Politècnica de València. \\ Camí de Vera, s/n, 46022 Valencia, España \\ franmihi@alumni.uv.es
}

\section{RESUMEN}

A partir de un enfoque cuantitativo consistente en fotointerpretar imágenes aéreas mediante técnicas SIG, complementado con un enfoque cualitativo (trabajo de campo y bibliográfico) se lleva a cabo un estudio diacrónico (1956, 1977, 1991 y 2012) de coberturas de usos del suelo en el término de Paterna, municipio de la corona metropolitana de València. A partir de este análisis multimétodo se analiza la dinámica territorial del municipio a lo largo del último medio siglo y se valora el efecto de la acción antrópica en Paterna. Se observa como desde 1960 su población se ha quintuplicado y su superficie artificial se ha multiplicado por ocho. Su crecimiento ha sido heterogéneo, y en la actualidad sus usos del suelo más destacados son el tejido urbano continuo y discontinuo, sus áreas comerciales e industriales y, sobre todo, sus centros de innovación tecnológica.

Palabras Clave: Paterna, SIG, dinámica territorial, fotointerpretación, acción antrópica.

\section{LAND USE DYNAMICS IN PATERNA (HORTA DE VALÈNCIA, SPAIN). FROM URBAN PERIPHERY TO INNOVATIVE CENTER}

\section{ABSTRACT}

Based on a quantitative approach consisting in photo-interpreting aerial images using GIS techniques, complemented by a qualitative approach (fieldwork and bibliography), a diachronic study (1956, 1977, 1991 and 2012) is carried out about land use cover in the municipality of Paterna, belonging to the metropolitan area of València (Spain). Based on this multi-method analysis, territorial dynamics of this town are analyzed over the last half century as well as the effect of anthropic action. It can be observed that since 1960 Paterna population has increased fivefold and its artificial surface has multiplied eightfold. Its growth has been heterogeneous, and today its most outstanding land uses are the continuous and discontinuous urban fabric, its commercial and industrial areas and, above all, its centers of technological innovation. 
Membrado-Tena, J.C., Hinojosa Sancho, F. M., (2018): Evolución de los usos del suelo en Paterna (Horta de València). De periferia urbana a centro innovador", GeoFocus (Artículos), no 22, p. 141-161. ISSN: 1578-5157 http://dx.doi.org/10.21138/GF.603

Key Words: Paterna, GIS, territorial dynamics, photo-interpretation, anthropic action.

\section{Introducción}

A partir de y de fotogramas aéreos de diversas épocas (1956, 1977, 1991 y 2012) se lleva a cabo un análisis de la evolución de los usos del suelo del municipio de Paterna, uno de los principales núcleos de descongestión industrial, comercial y residencial de la ciudad de València a lo largo del último medio siglo. Para ello, se emplean análisis basados en sistemas de información geográfica (SIG) que cuantifican cada tipo de uso de suelo fotointerpretado; posteriormente cada uso del suelo es catalogado a partir de una clasificación de tipos de cobertura creada ad hoc, y basada primordialmente en la de CORINE Land Cover. Este tratamiento de la información nos permite analizar la dinámica territorial de Paterna de una forma más precisa.

El objetivo principal de este artículo es, por tanto, la cuantificación de los cambios en los usos del suelo de Paterna durante los periodos citados, con el fin de analizar qué procesos y qué efectos tuvieron lugar en su término municipal a causa de la acción antrópica a lo largo de los cuatro periodos mencionados.

\subsection{Estado de la cuestión}

Una de las herramientas más productivas para analizar los cambios de usos del suelo de un territorio, con el consecuente impacto sobre el medio ambiente, deriva de la fotointerpretación de imágenes aéreas que muestren el estado de las coberturas del suelo antes y después de los principales cambios producidos.

Este tipo de evaluación permite un análisis cuantitativo que detecta el desarrollo de ciertas coberturas (las urbanas, en nuestro caso de estudio) en detrimento de otras (como son las forestales o las agrícolas), y que debe ser complementado con un análisis cualitativo derivado del trabajo de campo y bibliográfico.

Las técnicas de fotointerpretación utilizadas para este tipo de análisis han ido sofisticándose a lo largo de las últimas décadas, y en la actualidad es frecuente el uso de imágenes aéreas de alta resolución gestionadas mediante Sistemas de Información Geográfica para llevar a cabo este tipo de análisis cuantitativo.

Entre los trabajos que se han llevado a cabo al respecto en la última década cabe mencionar los de Bocco et al. (2001), Santana y Salas (2007), Aldana y Bosque (2008), Fernández y Prados (2010), Bea at al. (2013), Regil at al. (2015), Membrado-Tena y Serrano (2018) y Morell-Monzó y Membrado-Tena (2019).

\subsection{Caso de estudio}

Hemos elegido el municipio de Paterna como caso de estudio al tratarse de uno de los municipios del área metropolitana de València con mayor extensión (casi $36 \mathrm{~km}^{2}$ ) y expansión demográfica reciente (menos de 10.000 hab. en 1950 y casi 70.000 en la actualidad). Gracias a su tamaño, proximidad a la capital valentina, accesibilidad (junto a la A-7 E-15, la CV-35 y la V-30), y al valor relativamente barato de su suelo (ya que tradicionalmente abundaba el monte bajo y la agricultura de secano y no la rica huerta de regadío), Paterna ha experimentado un 


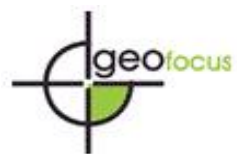

Membrado-Tena, J.C., Hinojosa Sancho, F. M., (2018): Evolución de los usos del suelo en Paterna (Horta de València). De periferia urbana a centro innovador", GeoFocus (Artículos), no 22, p. 113-112. ISSN: 1578-5157 http://dx.doi.org/10.21138/GF.603

extraordinario desarrollo industrial, comercial, urbano y suburbano y se ha convertido en paradigma de municipio de descongestión de la ciudad de València. La población de Paterna era de 67.854 habitantes en 2016 (INE). Históricamente su término municipal sumaba 40,48 km², pero tras la segregación de Sant Antoni de Benagéber en 1998 se redujo a 35,85 km² (figura 1).

Paterna forma parte de la comarca de l'Horta, cuya capital es la ciudad de València. A su vez, se enmarca en la subcomarca de l'Horta Oest, la más industrial de l'Horta. Desde el punto de vista funcional, Paterna forma parte del Área Metropolitana de València (AMV), que supera ampliamente los límites comarcales de l'Horta. El AMV es la mayor región por población y actividad económica del País Valenciano. Y dentro del AMV Paterna es el tercer municipio más poblado, tras València y Torrent, y el primero por suelo industrial.

El AMV alberga una primera corona metropolitana, al este de la A-7 / E-15 (corredor mediterráneo), y una segunda al este de la CV-50 (Salom et al. 2015). Paterna está dividida entre la primera y la segunda corona metropolitana, ya que la A-7 / E-15 divide su término en dos mitades. Al este de la A-7 predominan las actividades industriales (Font del Gerro, l'Andana, València Parc Tecnològic, Parc Científic de la Universitat de València) y el poblamiento concentrado (casco urbano, Mas del Rosari, Lloma Llarga, Terramelar). Al oeste de la A-7, en cambio, prevalece el tejido urbano discontinuo (urbanización La Canyada) (figura $1)$.

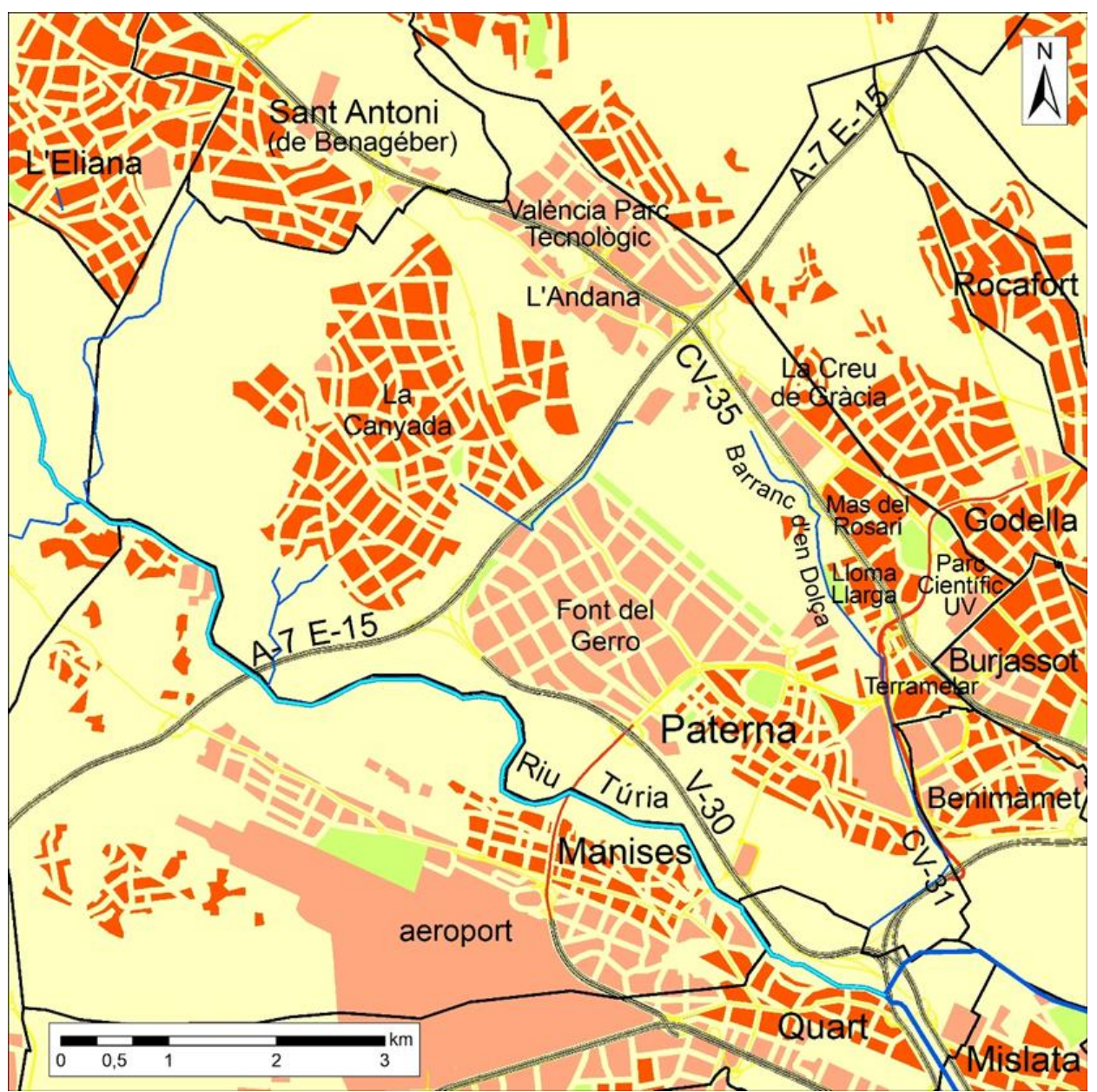

Figura 1. Término de Paterna

Fuente: elaboración propia 
Membrado-Tena, J.C., Hinojosa Sancho, F. M., (2018): Evolución de los usos del suelo en Paterna (Horta de València). De periferia urbana a centro innovador", GeoFocus (Artículos), no 22, p. 113-112. ISSN: 1578-5157 http://dx.doi.org/10.21138/GF.603

\subsection{Marco teórico}

Para poder entender y contextualizar mejor la evolución de los usos del suelo en las fechas elegidas $(1956,1978,1991,2016)$, hay que fijarse las políticas estatales de fomento del sector inmobiliario y de la construcción que, desde la segunda mitad del siglo XX, tanto han influido en la evolución de los usos del suelo de Paterna, y de tantos otros municipios metropolitanos españoles.

Para entender la evolución de los usos del suelo en España en el último siglo conviene retroceder al periodo de Autarquía franquista (1939-1950), caracterizado por la depresión, la escasez de todo tipo de bienes y por la interrupción drástica del proceso de modernización iniciado por el gobierno de la Segunda República (García-Delgado 1995). En materia del suelo la autarquía fue una etapa de penuria e infraproducción de viviendas que dejó un panorama desolador (Gaja 2005).

La década de 1950 fue un decenio bisagra, debido a que se produjo una vacilante liberalización y apertura al exterior. Gracias a la promulgación de la Ley del Suelo de 1956 el urbanismo pasó de ser entendido como un conjunto de facultades inherentes al derecho del propietario a convertirse en una función pública en la que prevalecía el "interés general" (García- Delgado 1995).

Durante el Desarrollismo franquista (1960-1974), fruto del Plan de Estabilización de 1959, se produjo un crecimiento de la economía española gracias a la apertura internacional del régimen franquista, a una coyuntura internacional favorable, y al bajo coste de la energía y de la mano de obra. Fue en este periodo cuando la Ley del Suelo de 1956 pasó a ser un instrumento en manos de propietarios y promotores inmobiliarios cuya finalidad era especulativa, ya que se basaba en unas expectativas económicas generadas por la revalorización que la calificación urbanística y la política "antipública" de la administración municipal y estatal permitían y fomentaban (Navarro 2000). Se trataba de una especulación inmobiliaria que partía de la Ley del Suelo como coartada, y que llenaba cada municipio de manchas urbanizables (turísticas, industriales, residenciales) que luego quedaban incompletas por falta de recursos o de clientela (Solà-Morales 1981). La Ley del Suelo de 1956 fue, en suma, un instrumento dirigido al fomento de un crecimiento continuo y que se pensaba infinito (Gaja 2005). Todo este mecanismo es el mismo que tuvo lugar durante la primera década del siglo XXI con la burbuja inmobiliaria española, cuyo estallido trajo unas consecuencias nefastas, como veremos más adelante.

El fin del desarrollismo vino marcado por la fuerte crisis del petróleo de 1973, que afectó gravemente a la economía española. Durante la Transición política (1975-1986) se vivió además la crisis de 1979, a las que se sumó la inestabilidad política. A continuación llegó el Primer boom inmobiliario (1986-1991), durante el cual el sector de la construcción entró en una fase expansiva. Para liderar la recuperación económica el gobierno socialista eligió al sector de la construcción, ya que moviliza mucha mano de obra. El Real Decreto-Ley 2/1985, también llamado Decreto Boyer, tenía como objetivo incrementar la compra de obras de nueva construcción, dar salida a las casas desocupadas mediante la liberalización del arrendamiento y estimular la inversión patrimonial. Durante este primer período de boom inmobiliario la demanda de segundas residencias en localidades litorales y en áreas de descongestión de las grandes ciudades fue notable. En este preciso periodo comenzó a desarrollarse el urbanismo expansivo (urban sprawl) en España, tanto en la costa como en las periferias metropolitanas. Este tipo de edificación basado en la baja densidad residencial supone un elevado coste 
Membrado-Tena, J.C., Hinojosa Sancho, F. M., (2018): Evolución de los usos del suelo en Paterna (Horta de València). De periferia urbana a centro innovador", GeoFocus (Artículos), no 22, p. 113-112. ISSN: 1578-5157

http://dx.doi.org/10.21138/GF.603

económico en infraestructuras (viarias, alcantarillado, luz, etc.) que disfrutan solo unos pocos (Burriel 2008, Membrado-Tena 2013).

Tras un periodo de crisis (1992-1996), derivado en parte del endeudamiento estatal ligado a los grandes eventos de 1992 (Expo de Sevilla, Olimpiadas de Barcelona, Capitalidad Europea de la Cultura en Madrid), dio comienzo el Segundo boom inmobiliario (1997-2007). Este fue el momento de máxima expansión del sector inmobiliario en España, que derivó en el desarrollo de una hiperurbanización, cuyo peor efecto a largo plazo será el agravamiento de la crisis ecológica (Gaja 2005). El exceso de producción inmobiliaria se puede ilustrar con datos: el boom inmobiliario alcanzó su punto máximo en 2006, año en que se construyeron más viviendas en España que en la suma de Italia, Reino Unido y Alemania, tres estados más poblados y ricos que el nuestro (Membrado-Tena 2015).

El gran incremento de viviendas en España se puede explicar por dos factores principales. El primero es que, como miembro de la zona euro desde su creación en 1999, España disfrutó de los beneficios de formar parte de una divisa considerada fuerte y segura (Romero 2010). De esta forma fue fácil para los bancos y empresas obtener créditos en el extranjero. El segundo factor fue la aprobación en 1998 de una nueva Ley del Suelo, que permitía que cualquier suelo no protegido fuera edificable (Rullán 2011). La falta de un marco regulatorio adecuado permitió a los promotores privados construir tanto como quisieron. Ni las autoridades autonómicas ni estatales pudieron controlar este desarrollo urbano promovido por los municipios y por los intereses privados. Ni siquiera fueron capaces de atenuar su impacto en la sostenibilidad territorial (Burriel 2008).

La situación cambió drásticamente cuando las líneas de crédito se cortaron a mediados de 2007 debido a la crisis financiera internacional. En ese momento explotó la burbuja inmobiliaria, y se inició una crisis económica que puso fin a la expansión del sector inmobiliario (Membrado-Tena 2013).

Paterna es un municipio paradigmático a lo largo de las distintas etapas de crecimiento inmobiliario, como veremos en el apartado de resultados y discusión. Antes, mostraremos en el apartado de metodología los aspectos técnicos desarrollados en este artículo para obtener los mapas diacrónicos de evolución de los usos del suelo de su término y para la extracción de variables que cuantifiquen el proceso de transformación del municipio.

\section{Metodología}

Para analizar la evolución de los usos del suelo de Paterna nos basamos en un tipo de investigación de métodos mixtos (Membrado-Tena 2016). Por un lado, un enfoque cuantitativo y, por otro, uno cualitativo. Este último se basa en la bibliografía consultada, pero también en el trabajo de campo, la observación y percepción espontánea e intuitiva y el análisis crítico de las formas y modelos hallados sobre el terreno; por su parte, el análisis cuantitativo se apoya en una clasificación de usos del suelo, una fotointerpretación de dichos usos, y una cuantificación de los mismos a lo largo de cuatro momentos temporales (1956, 1977, 1991 y 2012). El método cuantitativo, propio del positivismo geográfico, es fruto de recientes y profundos progresos tecnológicos de la Geografía, frente al tradicional enfoque cualitativo de esta ciencia (MorenoJiménez 2004, Moreno-Jiménez 2013). Pasamos a explicar a continuación la clasificación de usos del suelo que hemos creado expresamente para este artículo. 
Membrado-Tena, J.C., Hinojosa Sancho, F. M., (2018): Evolución de los usos del suelo en Paterna (Horta de València). De periferia urbana a centro innovador", GeoFocus (Artículos), no 22, p. 113-112. ISSN: 1578-5157 http://dx.doi.org/10.21138/GF.603

\subsection{Base de datos de Uso del Suelo ad hoc}

Uno de los pasos del proceso de trabajo para la obtención de mapas del término de Paterna ha sido la cuantificación de las coberturas del suelo a lo largo de las cuatro épocas que hemos señalado.

Para ello, a partir de software ArcGIS 10.2, fotointerpretamos y creamos mapas de coberturas del suelo que van asociados a una base de datos interna que nos permiten relacionar el tipo de suelo que definamos en el mapa con su superficie correspondiente en el término. Antes de ejecutar la fotointerpretación debemos decidir qué clasificación de coberturas del suelo vamos a seguir para nuestros mapas. La nomenclatura de dicha clasificación se inspira en la de CORINE Land Cover (CLC), que es una cartografía de usos del suelo iniciada en 1985 (año de referencia 1990) y actualizada en 2000, 2006 y 2012. Consiste en un inventario de cobertura terrestre compuesto por 44 clases de usos del suelo distintas. CLC utiliza una Unidad de Mapeo Mínimo (UMM) de 25 ha para fenómenos de área (Copernicus, 2018).La principal diferencia entre nuestra clasificación ad hoc y la de CLC es que las unidades mínimas de mapeo en nuestra cartografía son menores a las del CLC (tablas 1 y 2), ya que esta es una cartografía de usos del suelo a escala europea y aquí trabajamos a escala municipal y, por lo tanto, buscamos más detalle.

Para crear la nomenclatura tenemos en cuenta el tipo de imágenes que empleamos y su resolución; el nivel de generalización (unidad mínima de superficie que asignemos a cada entidad de cobertura); el tipo de tramado que asignemos a cada cobertura en la leyenda; y la escala (Membrado-Tena 2012). En las tablas 1 y 2 mostramos, respectivamente, las características técnicas y la nomenclatura de la base de usos del suelo creada ad hoc para la fotointerpretación de los usos del suelo del término de Paterna.

Tabla 1. Características técnicas de la cartografía usada y de CORINE Land Cover (CLC)

\begin{tabular}{|l|l|}
\hline \multirow{2}{*}{ Características de los mapas resultantes y de CORINE Land Cover (CLC) } \\
\cline { 2 - 2 } & Mapas resultantes 1.50.000 \\
\cline { 2 - 2 } & Vuelo americano 1:33.000 \\
\cline { 2 - 2 } & Vuelo IRYDA 1:18.000 \\
\cline { 2 - 2 } & Vuelo valenciano 1991 1:25.000 \\
\cline { 2 - 2 } & Ortofotografía aérea (PNOA) a máx. res. 2012 1: 10.000 \\
\hline Escala de Referencia CLC & $1: 100.000$ \\
\hline Sistema geodésico de referencia & ETRS89 \\
\hline Sistema geodésico de referencia CLC & ETRS89 \\
\hline Sistema cartográfico de referencia & UTM Zona 30N \\
\hline Sistema cartográfico de referencia CLC & UTM Zona 30N \\
\hline Imágenes de referencia 1956 & Imágenes aéreas- Vuelo americano (1956) \\
\hline Imágenes de referencia 1977 & Vuelo IRYDA (1977) \\
\hline Imágenes de referencia 1991 & Vuelo valenciano (1991) \\
\hline Imágenes de referencia 2012 & Ortofotos PNOA a máxima resolución (50 cm) \\
\hline Imágenes de referencia CLC 1990 & Landsat TM \\
\hline Imágenes de referencia CLC 2000 & Landsat7 \\
\hline Imágenes de referencia CLC 2006 & SPOT4 \\
\hline Superficie mínima de mapeo & Entre 2-5 ha \\
\hline Superficie mínima de mapeo CLC & 25 ha (5 ha si hay cambio en uso del suelo) \\
\hline Clasificación jerárquica & 15 clases de coberturas (tres dígitos) \\
\hline Clasificación jerárquica CLC & 44 clases de coberturas (tres dígitos) \\
\hline & Fuente: elaboración propia \\
\hline
\end{tabular}


Membrado-Tena, J.C., Hinojosa Sancho, F. M., (2018): Evolución de los usos del suelo en Paterna (Horta de València). De periferia urbana a centro innovador", GeoFocus (Artículos), no 22, p. 113-112. ISSN: 1578-5157 http://dx.doi.org/10.21138/GF.603

Tabla 2. Sistema de Usos del Suelo Ad Hoc

\begin{tabular}{|c|c|c|c|c|}
\hline \multicolumn{5}{|c|}{ Nomenclatura } \\
\hline Nivel 1 CLC & \multicolumn{2}{|c|}{ Clase cartografía usada/ Nivel 2 CLC } & Nivel 3 CLC & $\mathrm{UMM}^{* *}$ \\
\hline \multirow{8}{*}{ Clase 1 (urbana) } & Clase 1.1 & Tejido urbano continuo & 111 & \multirow{8}{*}{$>2$} \\
\hline & Clase 1.2 & Tejido urbano discontinuo & 112 & \\
\hline & Clase 1.3 & Zona industrial & 121 & \\
\hline & Clase 1.4 & Zona de servicios & 121ㅁ* & \\
\hline & Clase 1.5 & Red viaria y ferroviaria & 122 & \\
\hline & Clase 1.6 & Zona de extracción minera & 131 & \\
\hline & Clase 1.7 & Zona en construcción & 133 & \\
\hline & Clase 1.8 & $\begin{array}{l}\text { Instalación deportiva y } \\
\text { recreativa }\end{array}$ & 142 & \\
\hline \multirow{4}{*}{ Clase 2 (agrícola) } & Clase 2.1 & Cultivo hortícola & 210 & \multirow{6}{*}{$>5$} \\
\hline & Clase 2.2 & Cítricos & $222 a^{*}$ & \\
\hline & Clase 2.3 & Cultivo arbóreo de secano & $222 b^{*}$ & \\
\hline & Clase 2.4 & Cultivo abandonado & 224 & \\
\hline \multirow[t]{2}{*}{ Clase 3 (forestal) } & Clase 3.1 & Bosque de conífera & 313 & \\
\hline & Clase 3.2 & Matorral boscoso de transición & 324 & \\
\hline $\begin{array}{l}\text { Clase } 4 \\
\text { (humedal) }\end{array}$ & ninguna & ninguna & ninguna & ninguna \\
\hline Clase 5 (agua) & Clase 5.1 & Lámina de agua (embalse) & 512 & $>2$ \\
\hline
\end{tabular}

Fuente: elaboración propia

\subsection{Georreferenciación}

El primer paso en este proceso consiste en la georreferenciación de los fotogramas aéreos escaneados de 1956, 1977 y 1991, con el fin de que todas las fotografías estén en un mismo sistema de coordenadas que nos permita comparar los usos del suelo en cada época analizada. El marco de coordenadas destino sobre el que nos apoyamos para georreferenciar las fotos de 1956, 1977 y 1991 es el que viene definido por las ortofotografías aéreas que descargamos del CNIG y que están orientadas en el sistema de referencia ETRS89, Datum ED50 Zona 30N (http://www.ign.es/ign/layoutIn/actividadesFotoTelePNOA.do).

El método que empleamos para relacionar el sistema de coordenadas origen definido por los fotogramas aéreos con el sistema de coordenadas destino o marco que establecemos con ortofotografías aéreas consistirá en la colocación de una serie de puntos de control a lo largo de ambas superficies. Los puntos de control consisten en puntos homólogos que relacionan zonas comunes entre ambos mapas. Un criterio de colocación de los puntos es apoyarse en lugares donde la acción antrópica haya intervenido, es decir, vértices o esquinas de parcelas de cultivo, cruces de carreteras, esquinas de edificaciones o intersecciones de caminos. Estos puntos de control debían de existir en 1956, 1977 y 1991 y seguir existiendo en la actualidad.

A la hora de distribuir sobre los dos mapas los puntos homólogos, estos hay que colocarlos repartidos sobre el mapa, ya que si focalizamos los puntos en una región en concreto del mapa, la proyección que obtendremos estará muy distorsionada. Desde la ventana de 
Membrado-Tena, J.C., Hinojosa Sancho, F. M., (2018): Evolución de los usos del suelo en Paterna (Horta de València). De periferia urbana a centro innovador", GeoFocus (Artículos), no 22, p. 113-112. ISSN: 1578-5157 http://dx.doi.org/10.21138/GF.603

georreferenciación (georreferencing) el software empleará un algoritmo matemático que nos permitirá saber cuál es el error medio cuadrático que hemos cometido. Este error medio cuadrático (e.m.c) es el resultado de las operaciones matemáticas que realiza el algoritmo para vincular ambos sistemas. Estas operaciones son tipos de transformación numéricas que permiten adaptar las coordenadas del sistema origen al sistema destino.

La tarea de colocación de los puntos de control resultó un tanto compleja en algunas zonas de los fotogramas de los periodos de 1956 y 1977 por falta de zonas urbanizadas o por la existencia de muchas zonas de cultivo. Se obtuvo un e.m.c superior al metro $(1,5-2) \mathrm{m}$. Para 1991 no hubo dificultades para situar los puntos de control y se obtuvo un e.m.c $<1 \mathrm{~m}$.

\subsection{Fotointerpretación y edición}

Una vez realizada la georreferenciación, pasamos a la fotointerpretación e identificación de los tipos de coberturas del suelo del municipio de Paterna. La documentación de partida acerca de la dinámica territorial de Paterna y los sistemas de usos del suelo CORINE y SIOSE nos habían aportado una aproximación acerca del tipo de coberturas que íbamos a encontrar en Paterna, pero no su localización y toponimia.

A continuación, para la edición de las coberturas identificadas se procedió, en primer lugar, a la edición de las vías de transporte: a partir de una capa auxiliar de tipo polilínea, se dibujó el eje de las principales vías de comunicación; después se efectuó un buffer de tantos metros como se requiriera en cada uno de los distintos ejes viarios trazados. Dicho buffer se ejecutó sobre una capa poligonal del término de Paterna, creada a partir de un shapefile municipal de España, descargable desde el CNIG. Este shapefile va a ser la capa base para el resto de la edición del mapa. Tras el buffer se efectuó un recorte con el fin de "vaciar" la silueta de la capa base allí donde hubiese por encima un polígono lineal de carretera (fruto del anterior buffer).

Tras el buffer y el clip obtenemos un polígono multipart que deberemos "explotar" (con Explode Multipart, desde la barra de herramientas Advanced Editing) para preparar nuestra capa base para la edición del resto de coberturas del mapa. Las nuevas coberturas se obtendrán a partir de la herramienta "cortar" de la barra Editor.

Para la edición de coberturas del suelo, editamos la capa poligonal, y la vamos subdividiendo en función de los distintos usos que observamos en la ortofotografía. Una vez concluida la fotointerpretación, recurrimos a visores cartográficos y a visitas a campo para cerciorarnos de que nuestros mapas sean correctos.

Luego viene la fase de asignación de colores y tramas para cada una de las coberturas. En primer lugar, cumplimentamos la base de datos de nuestros mapas con el tipo y código de cobertura correspondiente, y calculamos su superficie. Después se asigna un color de paleta a cada una de las coberturas. Para ello, nos basamos en la leyenda que emplea CORINE (figura 2) (Membrado-Tena 2012). 
Membrado-Tena, J.C., Hinojosa Sancho, F. M., (2018): Evolución de los usos del suelo en Paterna (Horta de València). De periferia urbana a centro innovador", GeoFocus (Artículos), no 22, p. 113-112. ISSN: 1578-5157

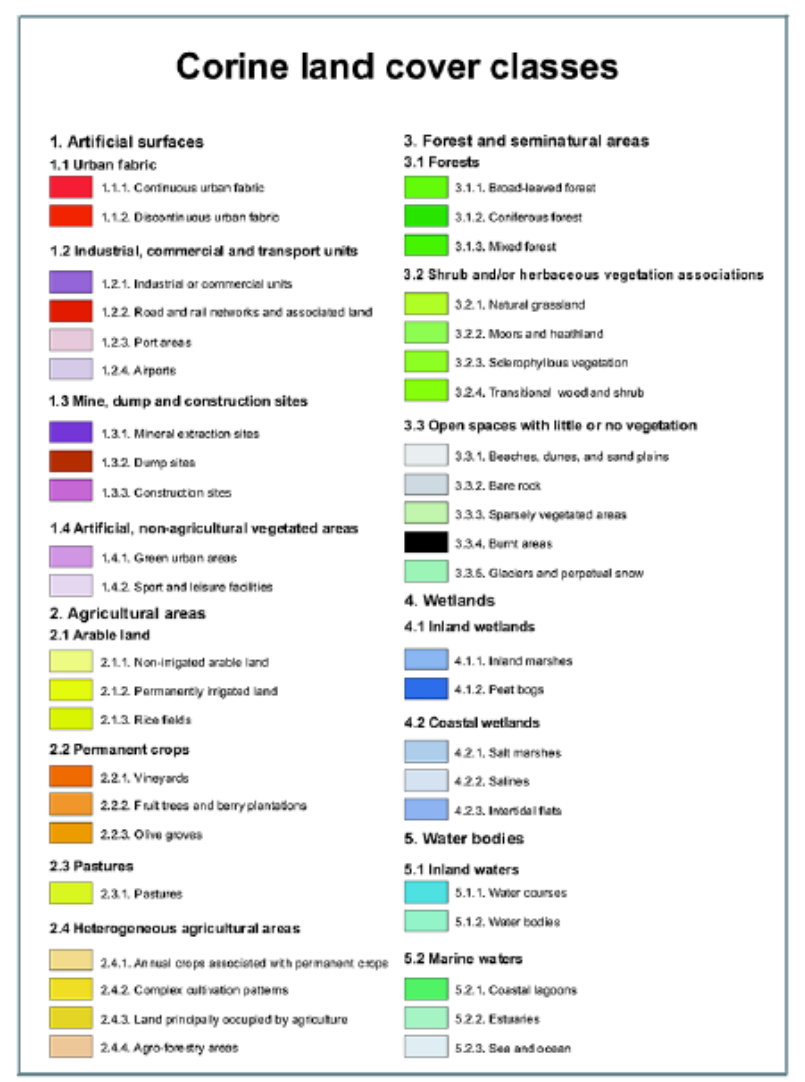

Figura 2. Leyenda de CORINE y sus tipos de coberturas. Fuente: CORINE Land Cover

\section{Resultados}

Una vez vista la metodología se procederá a mostrar y analizar los resultados obtenidos, a lo largo de los cuatro periodos mencionados, por lo que respecta a la dinámica territorial de Paterna.

\section{1.- 1956-1977}

Los datos de coberturas del año 1956 (figura 3, tabla 3) indican un predominio en Paterna del cultivo arbóreo de secano (algarrobos, olivos, viña y almendros) (1.434 ha), seguido por las coníferas (1.205 ha) y por los cítricos y, a mucha distancia, otros cultivos de regadío (huerta) (572 ha). Por lo tanto, Paterna era un municipio básicamente de secano y con abundantes pinares, siendo el regadío una parte poco significativa de su territorio, aunque importante desde el punto de vista económico. Un dato interesante a tener en cuenta en 1977 es la expansión del regadío (sobre todo cítricos), en detrimento de los cultivos arbóreos de secano: de las 572 ha de cultivos regados en 1956 se pasó a 980 ha en 1977 (figura 4, tabla 3). Este crecimiento de los cultivos de regadío sobre antiguos secanos se debió a la perforación de pozos para riego que permitían irrigar zonas tradicionales no regadas. 
Membrado-Tena, J.C., Hinojosa Sancho, F. M., (2018): Evolución de los usos del suelo en Paterna (Horta de València). De periferia urbana a centro innovador", GeoFocus (Artículos), no 22, p. 113-112. ISSN: 1578-5157

http://dx.doi.org/10.21138/GF.603

Por lo que respecta a las coberturas artificiales del suelo, cabe mencionar que Paterna contaba con 16.951 habitantes en 1960, frente a los 29.656 de 1975. Su población casi se duplica, lo cual se ve reflejado en un aumento de los suelos residenciales, industriales y de las redes de transporte (Boira et al. 1995).

Las vías de transporte más representativas en este periodo son el ferrocarril de València a Llíria, de vía estrecha, y las carreteras secundarias (carreteras comarcales) que comunican el municipio con sus vecinos. Entre estas últimas cabe destacar la C-234 (hoy CV-35) que atraviesa de este a oeste el término y que une Paterna con València, al este, y con Llíria, al oeste. Entre 1956 y 1977 se realizaron labores de acondicionamiento y ampliación de las vías de comunicación, cuya cobertura pasó de 70 ha a 82 entre las dos fechas.

El crecimiento de coberturas artificiales más espectacular fue el de la ciudad dispersa o de baja densidad (tejido urbano discontinuo), que pasó de ocupar 80 ha en 1956 a 386 ha en el año 1977, en detrimento de los cultivos de secano y de los bosques de coníferas. El inicio de este fenómeno urbanístico dará lugar a la ocupación de zonas de tipo residencial como La Canyada y Mas del Rosari; este último, que se destinó al principio a lugar de segunda residencia de veraneo, progresivamente se convirtió en suelo urbano continuo (barrio de La Coma).

El tejido urbano continuo también experimentó un gran crecimiento, pasando de 108 en 1956 a 238 ha en 1977. En el mapa de 1956 es posible diferenciar los límites del casco urbano de Paterna, bordeados por campos de regadío, al norte, y de secano, al sur. Posteriormente, el casco urbano de Paterna se prolongará en dirección este, conurbándose con el de Benimàmet (término de València) y quedando separados ambos por el barranc d'en Dolça (figura 1).

A lo largo de este periodo se observa además como en 1956 no existían zonas industriales ni comerciales, y, en cambio, en 1977 había 250 ha. Se puede apreciar en el mapa de 1977 el incipiente polígono de la Font del Gerro (oficialmente Fuente del Jarro), que será el germen manufacturero que convertirá a Paterna en uno de los mayores focos industriales valencianos. 
Membrado-Tena, J.C., Hinojosa Sancho, F. M., (2018): Evolución de los usos del suelo en Paterna (Horta de València). De periferia urbana a centro innovador", GeoFocus (Artículos), no 22, p. 113-112. ISSN: 1578-5157

Titulo: Mapa de Usos del Suelo del Término de Paterna - Año1956

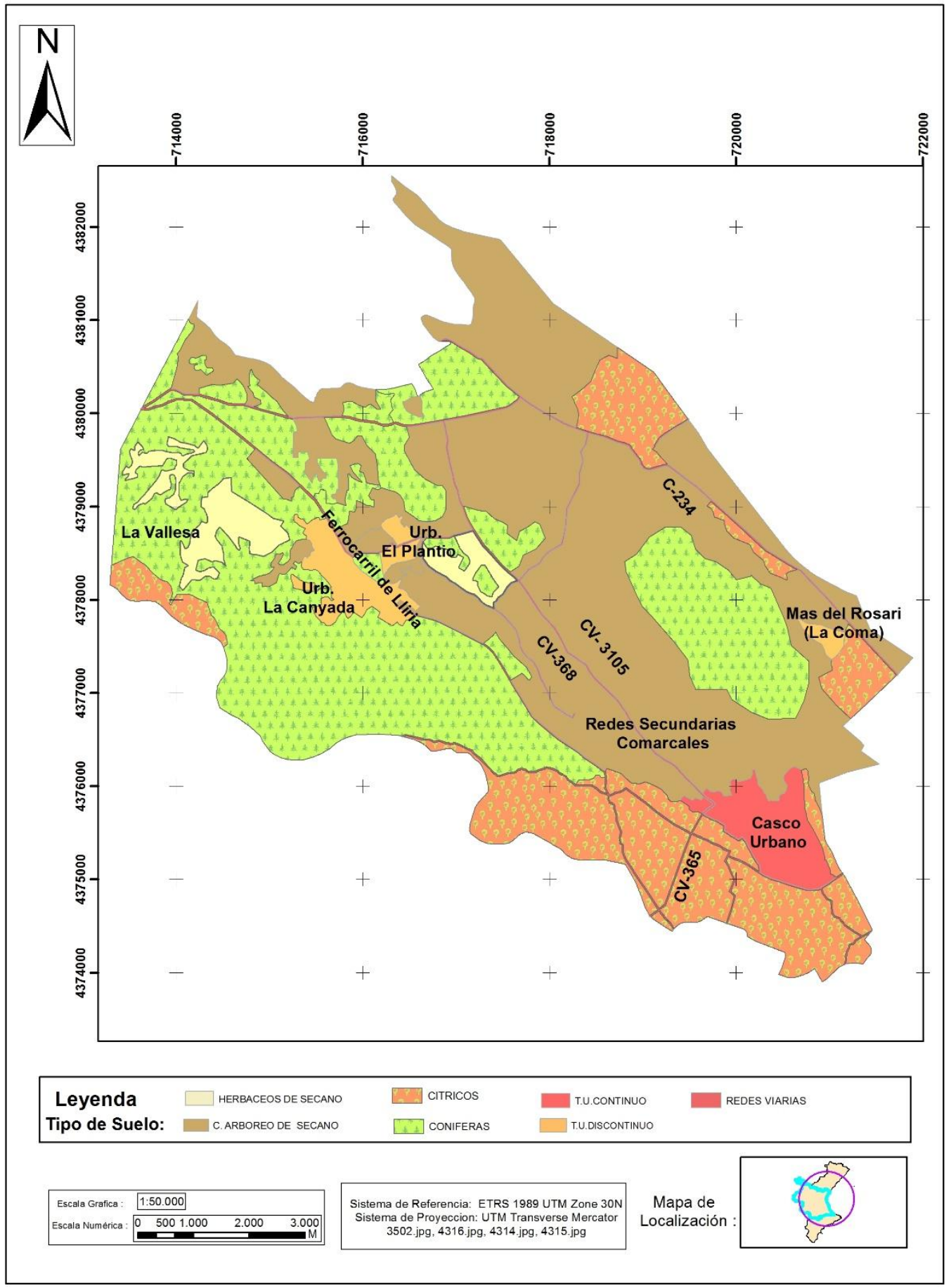

Figura 3. Mapa de coberturas de Usos del suelo-1956

Fuente: elaboración propia 
Membrado-Tena, J.C., Hinojosa Sancho, F. M., (2018): Evolución de los usos del suelo en Paterna (Horta de València). De periferia urbana a centro innovador", GeoFocus (Artículos), no 22, p. 113-112. ISSN: 1578-5157

Mapa de Usos del Suelo del Término de Paterna - Año 1977
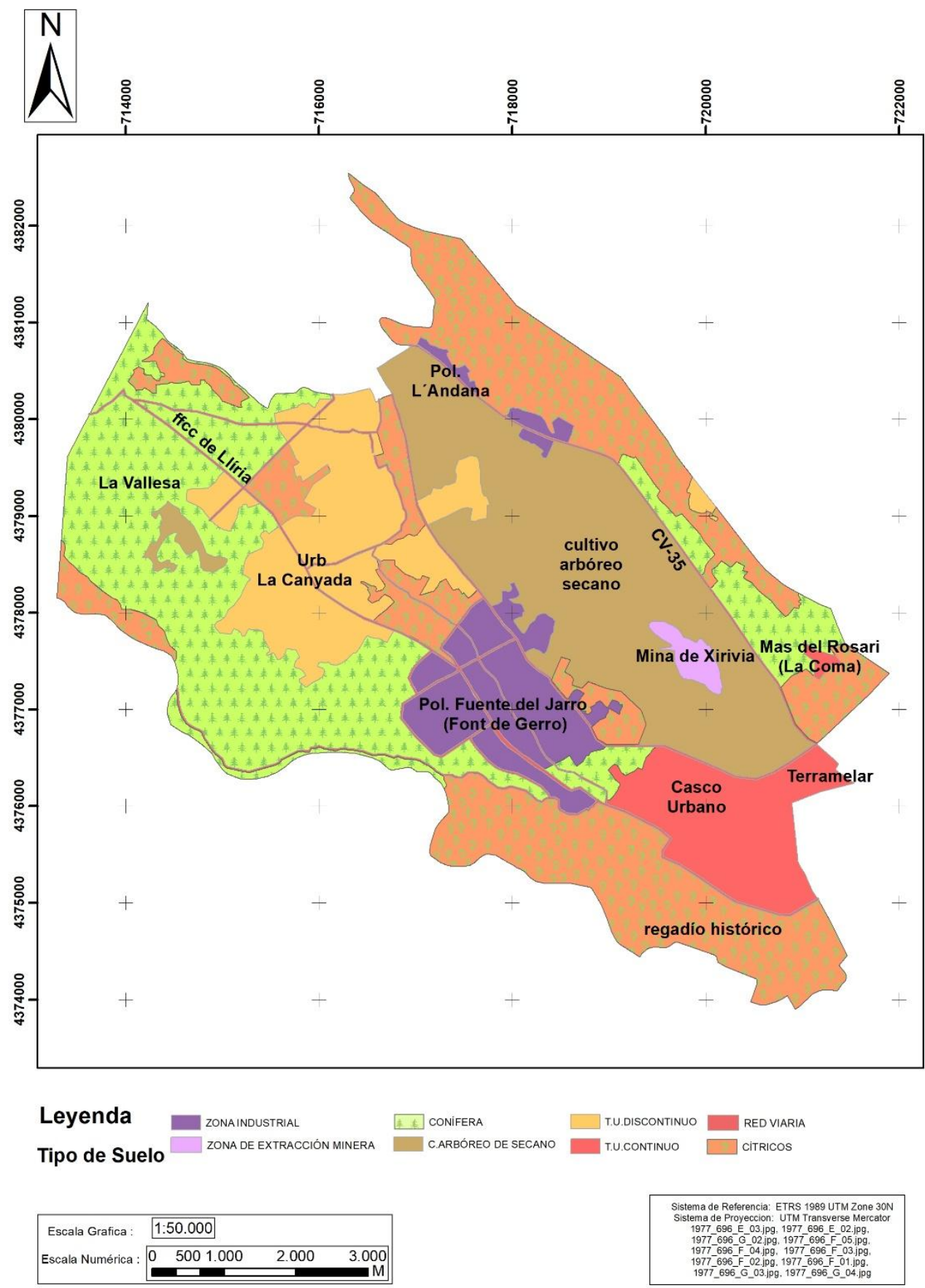

$\$$ CONIFERA

Figura 4. Mapa de coberturas de Usos del suelo-1977

Fuente: elaboración propia 
Membrado-Tena, J.C., Hinojosa Sancho, F. M., (2018): Evolución de los usos del suelo en Paterna (Horta de València). De periferia urbana a centro innovador", GeoFocus (Artículos), no 22, p. 113-112. ISSN: 1578-5157 http://dx.doi.org/10.21138/GF.603

\section{2.- $1977-1991$}

A lo largo de este periodo Paterna experimentó un nuevo aumento de la población (ca. 34.000 habitantes en 1980 y ca. 41.000 en 1991, según datos del INE) y, ligado a este, de las coberturas artificiales. La principal cobertura del suelo en 1991 era la de cítricos (606 ha), seguida del cultivo arbóreo de secano (586) y de las coníferas (561) (figura 5, tabla 3). Las tres coberturas descendieron respecto a 1977. El abandono de los cultivos arbóreos de secano, por falta de productividad, se acelerará durante los años siguientes, y acabará afectando también a los cultivos arbóreos de regadío (cítricos).

En cuanto a usos artificiales, todos crecen de manera notable, en detrimento de las coníferas y los cultivos. El suelo industrial pasa de 250 ha a 357, gracias a la ampliación de los polígonos industriales y a la creación de otros nuevos, como el València Parc Tecnològic. Paterna se consolida y refuerza como zona de descongestión industrial de la ciudad de València. Las vías de transporte más representativas en este periodo son el ferrocarril a Llíria; la N-335 (futura V-30) que conecta con el puerto de València; la CV-35, convertida en autovía, que permite un acceso a la capital en transporte privado en escasos 20 minutos; y la A7 / E15 (ByPass) o corredor mediterráneo, que mejora notablemente la accesibilidad a Paterna.

En 1977 el tejido urbano discontinuo había empezado a ocupar antiguos bosques de coníferas, y este hecho se había acentuado para 1991. Este fenómeno urbanístico dio lugar a la macrourbanización de la Canyada, que constituye una gran ciudad en sí misma, al margen del casco urbano de Paterna. Estas viviendas eran en 1977, en su mayor parte, segunda residencia o lugar de veraneo para residentes de la ciudad de València; sin embargo, en los años 90, con la mejora de las vías de comunicación, muchos de sus residentes decidieron establecerse allí todo el año.

Por su parte, el tejido urbano continuo no dejó de crecer, pasando de 214 ha en 1977 a 266 en 1991; esta expansión se produjo en el casco urbano, pero también en áreas periféricas desconectadas de este (Terramelar, la Coma), consistentes en grandes bloques de viviendas junto a la autovía CV-35. Llama la atención en 1991 el elevado número de suelo en construcción (236 ha) que, como veremos en el mapa de 2012, se tradujo en nuevos polígonos industriales y nuevos bloques de viviendas aisladas del casco urbano.

\section{3.- $1991-2012$}

Entre 1991 y 2012 Paterna registra el mayor crecimiento de población en términos absolutos en comparación con cualquiera de los otros tres periodos observados. Pasa de 41.000 habitantes en 1991 a 67.000 en 2013.

Los usos agrícolas continúan con su regresión: el abandono de los cultivos arbóreos se consuma casi en su totalidad, mientras los cítricos descienden de 606 ha en 1991 a 386 en 2012. En 2012 es mayor la cantidad de cultivos abandonados (570 ha) que en producción (409 ha), que solo sobreviven decentemente en las áreas históricas de regadío, al sur del casco urbano. En cambio, las coníferas apenas experimentan cambios, ya que la zona boscosa de la Canyada y la Vallesa pasa a integrarse dentro del Parque Natural del Túria y, por tanto, se convierte en zona protegida no urbanizable (figura 6 , tabla 3 ).

Los usos artificiales siguen creciendo, al calor de la burbuja inmobiliaria. El tejido urbano discontinuo crece, aunque menos que en las décadas anteriores; la urbanización de la Canyada 
Membrado-Tena, J.C., Hinojosa Sancho, F. M., (2018): Evolución de los usos del suelo en Paterna (Horta de València). De periferia urbana a centro innovador", GeoFocus (Artículos), no 22, p. 113-112. ISSN: 1578-5157 http://dx.doi.org/10.21138/GF.603

ya está muy consolidada, y se produce una cierta expansión de viviendas unifamiliares adosadas hacia el norte (urbanización de la Creu de Gràcia).

\section{Mapa de Usos del Suelo del Término de Paterna - Año 1991}

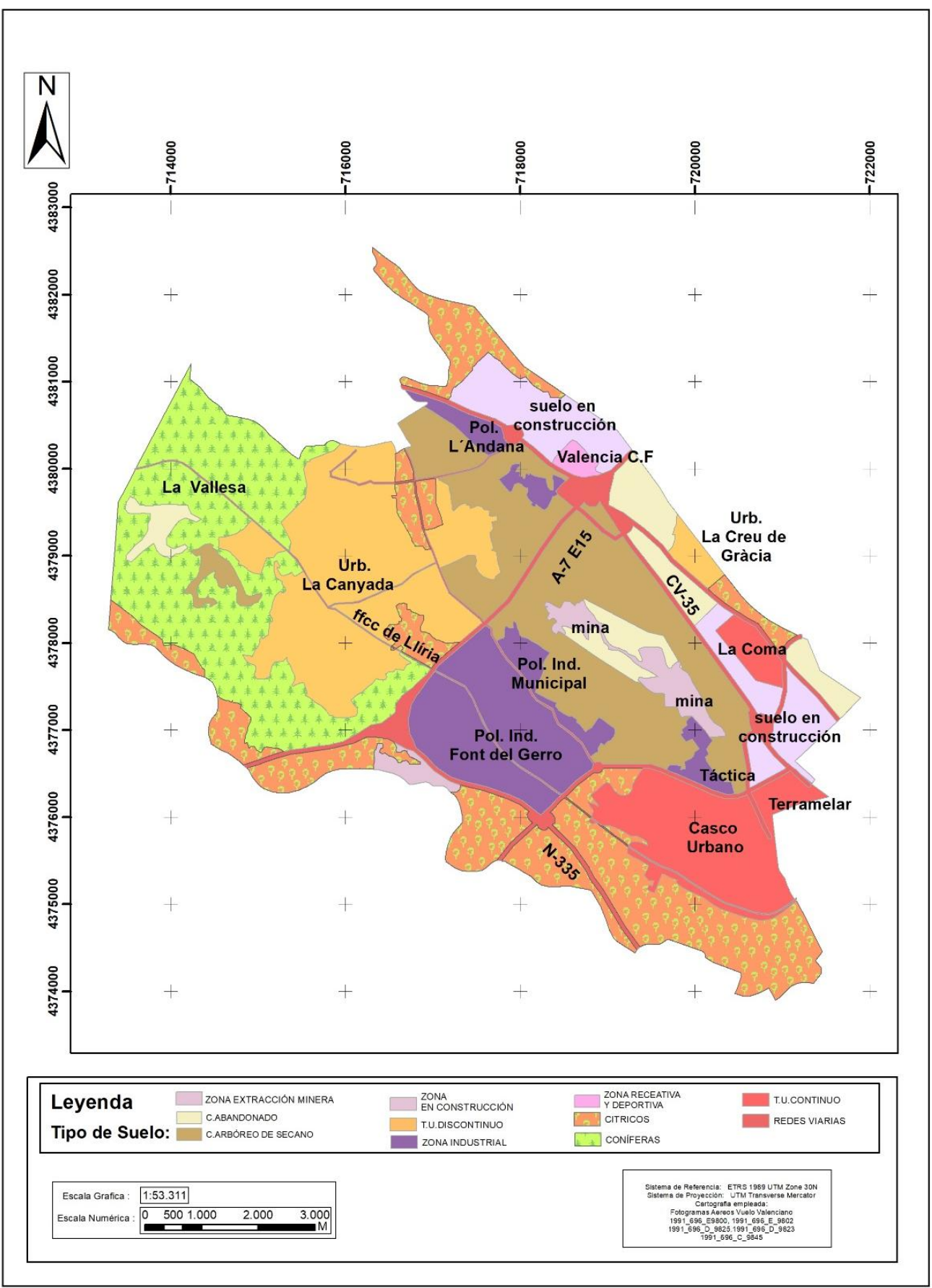

Figura 5. Mapa de coberturas de Usos del suelo-1991

Fuente: elaboración propia

El tejido urbano continuo pasa de 266 ha en 1991 a 396 en 2012, gracias a nuevos bloques de apartamentos cerca de la CV-35, especialmente en la Lloma Llarga y el Mas del 
Membrado-Tena, J.C., Hinojosa Sancho, F. M., (2018): Evolución de los usos del suelo en Paterna (Horta de València). De periferia urbana a centro innovador", GeoFocus (Artículos), no 22, p. 113-112. ISSN: 1578-5157 http://dx.doi.org/10.21138/GF.603

Rosari, que se convierten en ciudades dormitorio para residentes valentinos. Los polígonos industriales y de servicios crecen rápidamente, en detrimento de los cultivos: de 357 ha en 1991 se pasa a 814 en 2012. Se construyen centros de ocio y comerciales, como Heron City, pero también se amplía el València Parc Tecnològic y los polígonos de la Font del Gerro y l'Andana. Además, se crea el Parc Científic de la Universitat de València (figura 6, tabla 3).

\section{Mapa de Usos del Suelo del Término de Paterna - Año 2012}

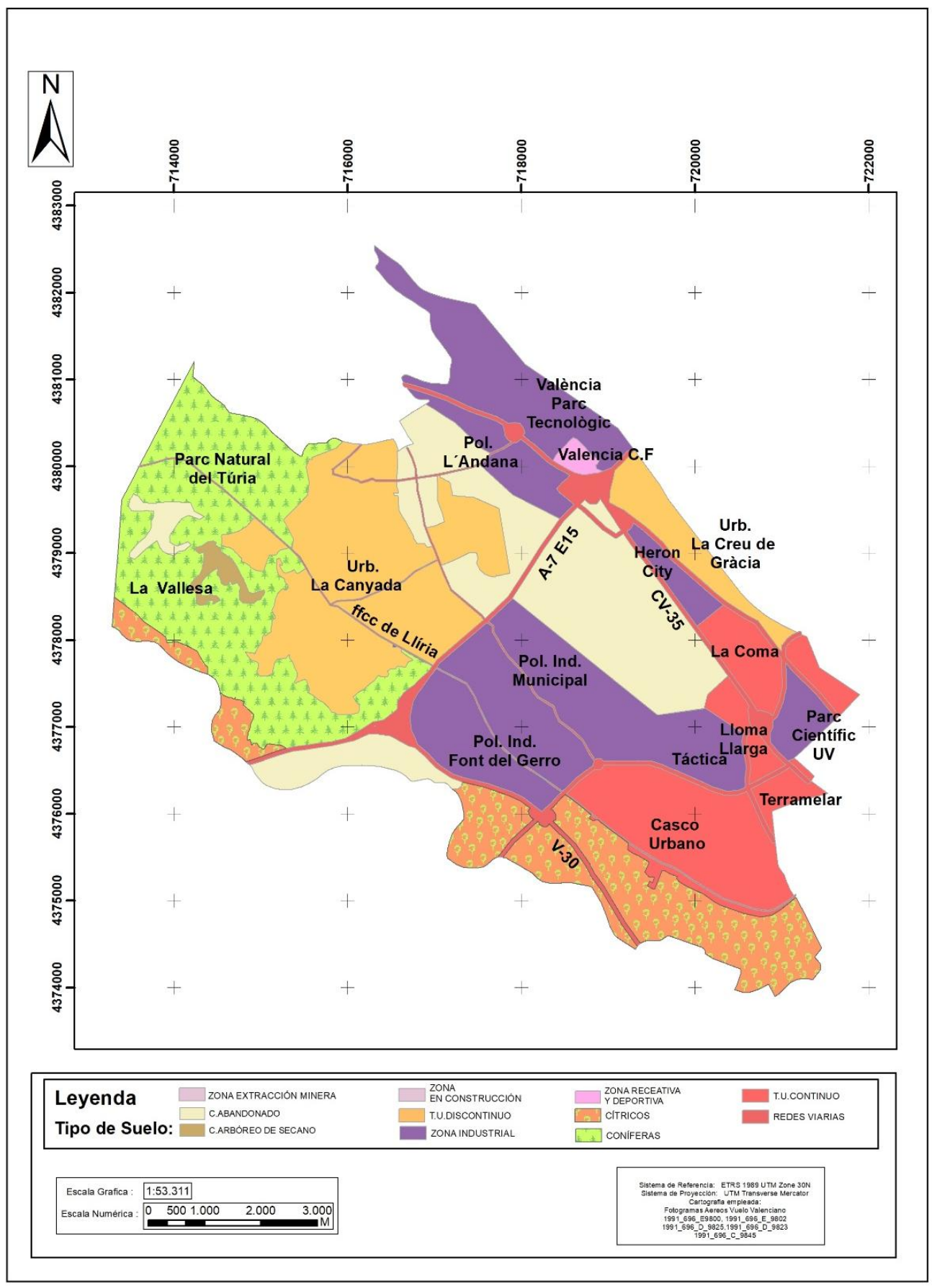

Figura 6. Mapa de coberturas de Usos del suelo-2012

Fuente: elaboración propia 
Membrado-Tena, J.C., Hinojosa Sancho, F. M., (2018): Evolución de los usos del suelo en Paterna (Horta de València). De periferia urbana a centro innovador", GeoFocus (Artículos), no 22, p. 113-112. ISSN: 1578-5157 http://dx.doi.org/10.21138/GF.603

\section{Discusión}

Tabla 3. Evolución de los usos del suelo en Paterna

\begin{tabular}{|l|r|r|r|r|r|r|r|r|}
\hline \multicolumn{1}{|c|}{ Uso del suelo } & ha 1956 & $\%$ & ha 1977 & $\%$ & ha 1991 & $\%$ & ha 2012 & $\%$ \\
\hline Redes viarias & 70 & 1,95 & 82 & 2,29 & 207 & 5,77 & 207 & 5,77 \\
\hline Cultivo abandonado & 0 & 0,00 & 0 & 0,00 & 175 & 4,88 & 582 & 16,23 \\
\hline Cítricos & 572 & 15,96 & 980 & 27,34 & 606 & 16,90 & 386 & 10,77 \\
\hline Tejido urbano continuo & 108 & 3,01 & 214 & 5,97 & 266 & 7,42 & 396 & 11,05 \\
\hline Bosque de coníferas & 1205 & 33,61 & 886 & 24,71 & 561 & 15,65 & 561 & 15,65 \\
\hline Cultivo arbóreo de secano & 1434 & 40,00 & 739 & 20,61 & 586 & 16,35 & 23 & 0,64 \\
\hline Tejido urbano discontinuo & 80 & 2,23 & 386 & 10,77 & 515 & 14,37 & 616 & 17,18 \\
\hline Zona industrial y servicios & 0 & 0,00 & 250 & 6,97 & 357 & 9,96 & 814 & 22,71 \\
\hline Otros* & 116 & 3,24 & 48 & 1,34 & 312 & 8,70 & 0 & 0,00 \\
\hline Total & 3585 & 100 & 3585 & 100 & 3585 & 100 & 3585 & 100 \\
\hline *zona en construcción, zona de extracción minera, herbáceos de secano. & & \\
\hline
\end{tabular}

Fuente: elaboración propia

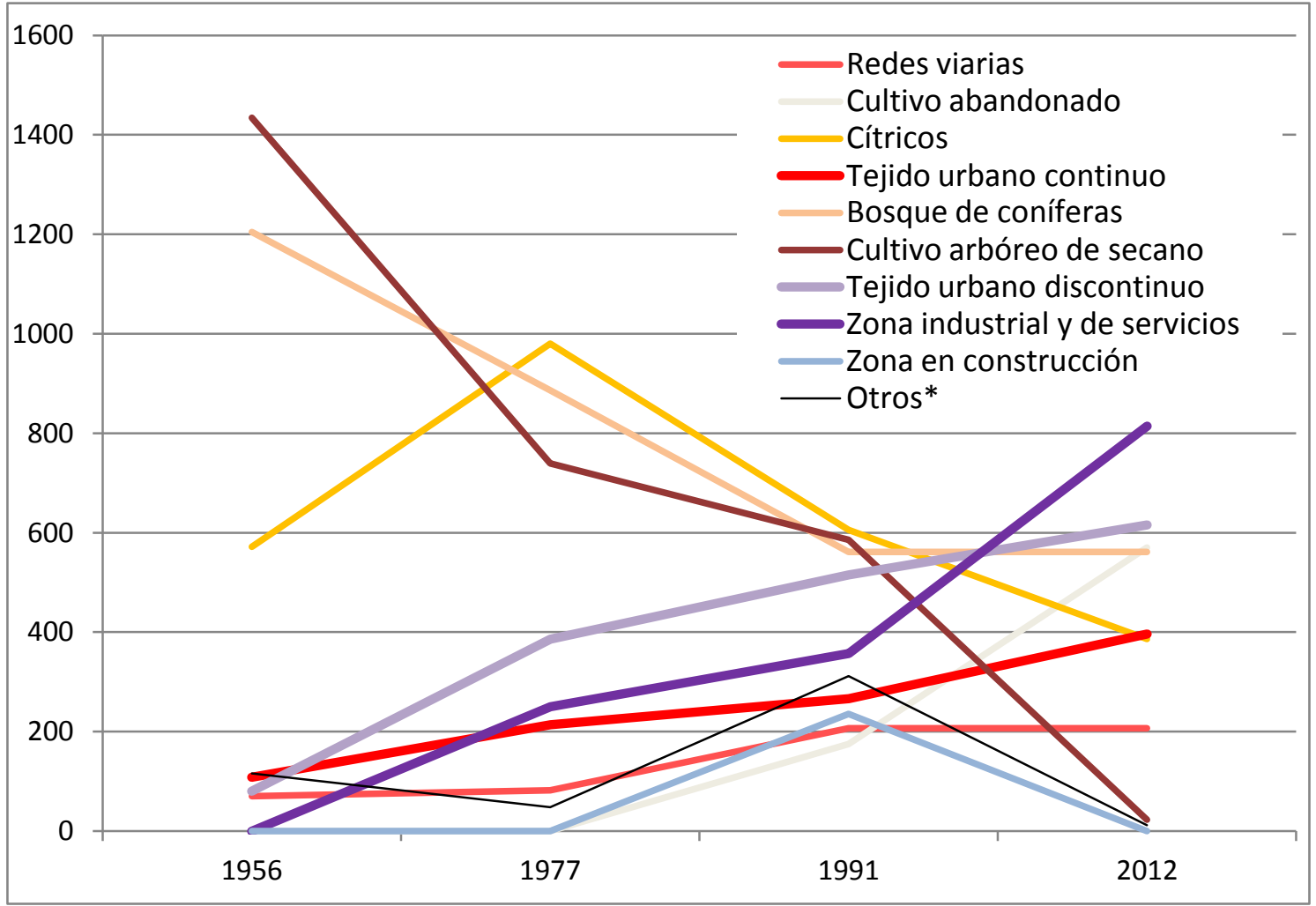

Figura 7. Evolución de los usos del suelo en Paterna

Fuente: elaboración propia

A partir de los resultados podemos analizar qué procesos y efectos tuvieron lugar en el término de Paterna a causa de la acción antrópica a lo largo de los cuatro periodos mencionados, donde el hecho más remarcable es la progresiva desaparición de la agricultura -principalmente la de secano- y su sustitución con el paso de los años por usos de carácter industrial, comercial y 
Membrado-Tena, J.C., Hinojosa Sancho, F. M., (2018): Evolución de los usos del suelo en Paterna (Horta de València). De periferia urbana a centro innovador", GeoFocus (Artículos), no 22, p. 113-112. ISSN: 1578-5157 http://dx.doi.org/10.21138/GF.603

urbano. En efecto, tanto en la tabla 3 como en la figura 7 se observa como los cultivos arbóreos de secano, que tienen menos valor que los de regadío y mucho menos que los usos urbanoindustriales, han ido decreciendo de manera brusca hasta convertirse en residuales. Los cítricos, antaño bien cotizados en el mercado, tuvieron un auge hasta 1977, pero durante las siguientes décadas también experimentaron un declive ante su falta de rentabilidad y el auge de otras actividades más lucrativas. Entre estas últimas cabe destacar el tejido urbano continuo (casco urbano), el tejido urbano discontinuo (urbanizaciones) y las zonas industriales y comerciales. A continuación, discutimos con más detalle estos cambios.

En 1956 Paterna era todavía eminentemente rural y su población era cinco veces menor a la actual. A pesar de que la comarca de Paterna es l'Horta de València, cuyo topónimo apela a la "huerta" (es decir, a los herbáceos de regadío), la mayor parte de sus suelos en 1956 eran cultivos de secano (algarrobos, olivos, viña y almendros) o bosques de coníferas. Paterna, junto con otras áreas periféricas de la comarca de l'Horta (Manises, Quart, Aldaia, Torrent...), albergaba gran cantidad de suelo agrícola de secano y, por ello, menos productivo y más barato que la huerta regada por las aguas del Túria, predominantes en la ciudad de València y en su periferia más inmediata. Este hecho, que en principio era un hándicap, se convirtió en la década de 1960 y posteriores en una ventaja competitiva, ya que el precio del suelo del secano era mucho más barato. Además, el daño patrimonial era mucho menor si se urbanizaban tierras agrícolas de secano (más abundantes y con cultivos cambiantes en función del mercado), que la valiosa, milenaria y amenazada huerta de València. Cabe señalar que, a pesar de la masiva ocupación antrópica del secano de Paterna, la huerta de València no quedó exenta de destrucción, ya que por el sur fue devorada por el llamado Plan Sur (construcción del nuevo cauce del río Túria), y por el norte se vio afectada por la expansión urbana y la de los campus universitarios (Membrado-Tena 2014). La propia huerta histórica de Paterna también se vio afectada por la construcción de la V-30, una infraestructura ligada al mencionado Plan Sur.

Por lo que se refiere a la abundancia de suelos boscosos (coníferas) en Paterna en 1956, al estar cerca de la ciudad de València $(\mathrm{a} 13 \mathrm{~km})$ y bien comunicados con ella a través del ferrocarril de vía estrecha de Llíria, algunos promotores inmobiliarios pronto pusieron sus ojos en ellos para convertirlos en un área de expansión inmobiliaria para segunda residencia de la burguesía valentina. Durante la Segunda República, el ilustre periodista y escritor valenciano Vicent Miguel Carceller, director de la revista La Traca, había comenzado ya la promoción de la urbanización llamada la Canyada. Este popular escritor satírico fue trágicamente fusilado en 1940 en Paterna por el régimen franquista, cuya etapa autárquica (1939-1950) se caracterizó por la escasez y la interrupción del proceso de modernización iniciado por el gobierno republicano.

La Ley del Suelo de 1956, el Plan de Estabilización de 1959 y el auge inmobiliario desarrollista de 1960-1974 tuvieron su reflejo en el notable crecimiento industrial y residencial de Paterna. A partir de 1960, este municipio comienza a ganar protagonismo como área de descongestión urbana de la ciudad de València. La urbanización de la Canyada se reactiva como área de segunda vivienda, tras el parón de la postguerra y la autarquía. Por otro lado, fruto de la descongestión fabril de la ciudad de València, el polígono industrial de la Font del Gerro de Paterna experimenta un espectacular desarrollo, en detrimento de los suelos arbóreos de secano.

El boom inmobiliario de 1986-1991, durante el cual el sector de la construcción entró en una fase expansiva, supuso para Paterna un nuevo impulso urbanizador, tras el parón por la crisis tardofranquista y los años convulsos de la transición. En 1991 el término de Paterna había visto ampliados sus polígonos industriales y comerciales, así como sus áreas de segunda 
Membrado-Tena, J.C., Hinojosa Sancho, F. M., (2018): Evolución de los usos del suelo en Paterna (Horta de València). De periferia urbana a centro innovador", GeoFocus (Artículos), no 22, p. 113-112. ISSN: 1578-5157 http://dx.doi.org/10.21138/GF.603

residencia de tipo unifamiliar, ocupadas mayormente por gente de la ciudad de València que, debido a la mejora de la accesibilidad, empieza a usarla como vivienda principal. La urbanización de la Canyada ya estaba plenamente consolidada; en la actualidad es la más extensa y poblada del término de Paterna: sumaba 11.257 habitantes en 2016, sobre una superficie de 610 hectáreas, frente a los 37.390 del casco urbano (más del triple de población que la Canyada) sobre 220 hectáreas (menos de una tercera parte de la superficie de la Canyada). Esta urbanización es un paradigma de urbanismo expansivo (urban sprawl), que supone un alto coste en infraestructuras de todo tipo para disfrute de unos pocos (MembradoTena 2015).

El mapa de 2012 ha variado muy poco respecto al actual (2018) debido al estallido de la burbuja inmobiliaria (2007) y a la crisis económica subsecuente. Dicho mapa muestra los efectos del segundo boom inmobiliario (1997-2007), que significó el más extenso y veloz desarrollo urbano de este y de muchos otros municipios españoles. La regresión de los cultivos fue tal que, por primera vez en las cuatro fechas estudiadas, una cobertura artificial era la que ocupaba una mayor extensión en Paterna (zona industrial y comercial); pero además también la segunda cobertura de mayor extensión pasó a ser de tipo artificial (tejido urbano discontinuo).

Paterna había adquirido en 2012 un enorme protagonismo a nivel autonómico valenciano debido a la riqueza y complejidad de su tejido productivo. Algunos de sus polígonos están especializados en la industria manufacturera, entre los cuales destaca por sus dimensiones el de la Font del Gerro. La suma de dicho polígono y de su contiguo polígono municipal supera las 400 hectáreas de suelo ocupado, lo que los convierte en el área industrial de mayores dimensiones de toda la corona metropolitana de València, superando incluso al polígono Ford de Almussafes (350 hectáreas) y al que se encuentra justo en el cruce de la A-3 con la A-7, en término de Riba-roja de Túria (Belenguer 2016). Dentro del País Valenciano, la extensión de la Font del Gerro solo es superada por el macropolígono azulejero de Onda (Plana de Castelló).

Frente al macropolígono de la Font del Gerro, cabe destacar otro polígono de Paterna de menor dimensión, pero más interesante desde el punto de vista cualitativo. Nos referimos al València Parc Tecnològic, que fue promovido, a final de la década de 1980, por la Generalitat Valenciana a través del IMPIVA (Institut de la Mitjana i Petita Indústria Valenciana), con el fin de albergar industrias de alta tecnología, así como centros de investigación, formación y desarrollo. Más reciente ha sido la creación del Parc Científic de la Universitat de València, iniciativa ligada a estrechar vínculos entre el potencial científico universitario y el sistema productivo, con el fin de fomentar procesos de innovación e impulsar empresas de base científico-técnica.

Paterna no solo es uno de los municipios con mayor peso industrial del País Valenciano, sino que, además, alberga su industria más innovadora. Paterna es para València lo que es Tres Cantos para Madrid, o Cerdanyola/Sant Cugat para Barcelona. Mientras que en los espacios industriales convencionales las ventajas de localización derivan de las economías de escala, que abaratan los costes, en los parques tecnológicos y científicos se localizan actividades basadas en la $\mathrm{I}+\mathrm{D}+\mathrm{i}$ donde la interacción entre empresas refuerza mutuamente los procesos de innovación (Ondátegui 2001).

Por lo que respecta al tejido urbano discontinuo, durante la burbuja inmobiliaria hubo un crecimiento moderado y alejado del saturado núcleo de la Canyada. En cambio, el tejido urbano continuo creció notablemente, si bien los nuevos edificios de la Lloma Llarga y del Mas del 
Membrado-Tena, J.C., Hinojosa Sancho, F. M., (2018): Evolución de los usos del suelo en Paterna (Horta de València). De periferia urbana a centro innovador", GeoFocus (Artículos), no 22, p. 113-112. ISSN: 1578-5157 http://dx.doi.org/10.21138/GF.603

Rosari, aislados del casco urbano y sin acceso peatonal al mismo, funcionan principalmente como barrios dormitorios de la ciudad de València, a la que están conectados a través de un tranvía.

Cabe señalar que en 2012 el suelo de Paterna había llegado ya a ser un cierto punto de saturación: por el sur se encuentra el casco urbano y la huerta histórica (plantada de naranjos); por el oeste se halla el parque natural del Túria; por el norte, había polígonos industriales y comercial y barrios residenciales aislados del casco urbano; por el centro el enorme polígono de la Font del Gerro y la macrourbanización de la Canyada.

Solo queda una bolsa de suelo por urbanizar al oeste de la autovía CV-35. Dicha bolsa de suelo era codiciada por un grupo inversor para llevar a cabo un macrocentro comercial y de ocio (Puerto Mediterráneo); sin embargo, la Generalitat Valenciana ha paralizado de momento el proyecto, por motivos medioambientales, ya que pretende desviar artificialmente el Barranc d'en Dolça, y porque, dada su envergadura, podría saturar las autovías CV-35 y CV-31 (figura $1)$.

\section{Conclusión}

A través de un estudio cuantitativo, basado en la tecnología de los sistemas de información geográfica, complementado con información cualitativa (trabajo de campo y consulta bibliográfica), hemos confeccionado un análisis diacrónico sobre los usos del suelo a escala municipal de Paterna.

Este enfoque multimetodológico de trabajo (cuantitativo y cualitativo) puede extrapolarse para el análisis de la dinámica territorial de cualquier otra localidad, si bien es especialmente significativo para aquellos municipios que durante el último medio siglo han experimentado profundos cambios. Desde 1960 hasta hoy las superficies artificiales han aumentado tanto o más que durante todo el periodo anterior a 1960 en Madrid y su periferia, en el corredor mediterráneo (tanto áreas urbano-industriales como turísticas), en el eje cantábrico y, en general, en la gran mayoría de ciudades españolas. Este aumento de las coberturas artificiales del suelo ha sido proporcionalmente mayor al crecimiento demográfico de las áreas concernidas. En Paterna la población se ha quintuplicado desde 1960 hasta hoy, pero sus superficies artificiales se han multiplicado por ocho durante el mismo periodo.

Cabe destacar como rasgo territorial de Paterna que el desarrollo de sus coberturas del suelo ha sido muy heterogéneo. Algunos municipios vecinos, como Godella, se han especializado en segundas residencias, mientras que Quart de Poblet ha desarrollado notablemente sus áreas industriales y comerciales; en cambio, en Paterna no se ha producido tal especialización. Allí encontramos una considerable diversidad de usos del suelo. Si a mitad del siglo XX predominaba el bosque de coníferas y los cultivos arbóreos de secano, en 2012 estos últimos habían desparecido, pero todavía existían importantes bolsas de suelo forestal (pinares), además de notables áreas de suelo urbano continuo (casco urbano y barrios aislados), tejido urbano discontinuo (chalets unifamiliares y también adosados), suelos agrícolas (citricultura), zonas comerciales $\mathrm{y}$ de ocio $\mathrm{y}$, por último, polígonos industriales, tanto dedicados a manufacturas convencionales, como a centros de producción y desarrollo tecnológico avanzado. Estos últimos configuran el sector productivo más original y atractivo del municipio, y dan a Paterna un especial valor añadido dentro de la Corona Metropolitana de València y, en general, dentro del País Valenciano y de toda España. 
Membrado-Tena, J.C., Hinojosa Sancho, F. M., (2018): Evolución de los usos del suelo en Paterna (Horta de València). De periferia urbana a centro innovador", GeoFocus (Artículos), no 22, p. 113-112. ISSN: 1578-5157 http://dx.doi.org/10.21138/GF.603

\section{Referencias bibliográficas}

Aldana, A. y Bosque, J. (2008): "Cambios ocurridos en la cobertura/uso de la tierra del Parque Nacional Sierra de la Culata. Mérida-Venezuela. Período 1988-2003", GeoFocus, 8, 139-168. http://www.geofocus.org/index.php/geofocus/article/view/141

Bea, M., Rodríguez, J. A. y Montesinos, S. (2013): “Uso de técnicas de información geográfica para la discriminación de superficies regadas", GeoFocus, 13-1, 220-245. http://www.geofocus.org/index.php/geofocus/article/view/268

Belenguer, M. Á. (2016): "Detección de problemas en la localización de usos del suelo mediante SIG y AHP: el caso de Riba-Roja de Túria (Valencia)", GeoFocus, 18, 3-24. http://www.geofocus.org/index.php/geofocus/article/view/438

Bocco, G., Mendoza, M. y Masera, O. (2001): "La dinámica del cambio de uso de suelo en Michoacán. Una propuesta metodológica para el estudio de los procesos de deforestación”, Investigaciones Geográficas (México), 44, 18-38.

Boira, J., Sales V. y Hermosilla, H. (1995): "Les comarques centrals (I): les valls del Palància i del Túria" en Piqueras, J. (ed.): Geografía de les Comarques Valencianes, III, 303-305.

Burriel, E. L. (2008): "La década prodigiosa del urbanismo español (1997-2006)", Scripta Nova, XII (270)(64). http://www.ub.edu/geocrit/sn/sn-270/sn-270-64.htm.

Copernicus (2018): CORINE Land Cover. https://land.copernicus.eu/pan-european/corine-landcoverFernández, M. y Prados, M. (2010): "Cambios en las coberturas y usos del suelo en la cuenca del río Guadalfeo (1975-1999)", GeoFocus, 10, 158-184. http://www.geofocus.org/index.php/geofocus/article/view/196

Gaja, F. (2005): Política de vivienda, suelo y urbanismo en la España del siglo XX. Bogotá: Universidad de los Andes.

García-Delgado, J. L. (1995): La economía española durante el franquismo. Temas para el debate.

Membrado-Tena, J.C. (2011): "SIOSE Valencia 2005: resultados, aplicaciones y comparación con CORINE", Cuadernos de Geografía, 89: 1-22.

Membrado-Tena, J.C. (2012): "Fotointerpretación del territorio y generalización cartográfica como herramienta para la educación geográfica" en De Miguel, R., De Lázaro, M. L. y Marrón, M. J. (coord.): La educación geográfica digital, 627-642.

Membrado-Tena, J.C. (2013): "Sunny Spain: migrantes del sol y urbanismo expansivo en el litoral mediterráneo español”. Ciudad y Territorio. Estudios Territoriales, XLV (178), 687-708.

Membrado-Tena, J.C. (2014): "L'expansió urbana a costa de l'horta" en La Universitat de València i els seus entorns: L'Horta de València, el Massís del Caroig, el Carrascal de la Font Roja i la Serra de Mariola, 20-23.

Membrado-Tena, J.C. (2015): "Migración residencial y urbanismo expansivo en el Mediterráneo español", Cuadernos de Turismo, 35, 259-286. http://revistas.um.es/turismo/article/view/221611

Membrado-Tena, J. C. (2016): "Identificación de orotopónimos irrelevantes mediante LIDAR", GeoFocus, 18, 25-46. http://www.geofocus.org/index.php/geofocus/article/view/463 
Membrado-Tena, J.C., Hinojosa Sancho, F. M., (2018): Evolución de los usos del suelo en Paterna (Horta de València). De periferia urbana a centro innovador", GeoFocus (Artículos), no 22, p. 113-112. ISSN: 1578-5157 http://dx.doi.org/10.21138/GF.603

Membrado-Tena, J. C. y Serrano, X. (2018): Evolució dels usos del sòl a Benicàssim (País Valencià). De l'estiueig elitista al turismo de masses. Treballs de la Societat Catalana de Geografia, 85, 197-216. http://revistes.iec.cat/index.php/TSCG/article/view/144862/143506

Morell-Monzó, S. y Membrado-Tena, J. C. (2019): "Causas y consecuencias del crecimiento urbanístico en el litoral valenciano a través de la evolución de los usos del suelo". El Caso de Oliva", Cuadernos de Turismo, 44 (en prensa).

Moreno-Jiménez, A. (2004): "Nuevas tecnologías de la información y revalorización del conocimiento geográfico", Scripta Nova, VII, 170 (62). http://www.ub.edu/geocrit/sn/sn-170$\underline{62 . h t m}$

Moreno-Jiménez, A. (2013): "Entendimiento y naturaleza de la cientificidad geotecnológica: una aproximación desde el pragmatismo epistemológico", Investigaciones Geográficas, 60, 536. http://rua.ua.es/dspace/handle/10045/34742

Navarro, F. y Vilanova, J. (2000). Transformació de la ciutat construïda, instruments urbanístics. Barcelona: edicions UPC.

Ondátegui, J. C. (2001): "Parques científicos y tecnológicos: los nuevos espacios productivos del futuro", Investigaciones Geográficas, 25, 95-118. https://rua.ua.es/dspace/bitstream/10045/374/1/Ondategui-Parques\%20cientificos.pdf

Regil, H.H., Franco, S., Nava, G.E., y Ordóñez, J.A.B. (2015): “Evaluación de las técnicas para el estudio del cambio de ocupación de suelo y propuesta metodológica para solventar algunas de sus inconsistencias: el Parque Nacional Nevado de Toluca, México", GeoFocus, 16, 61-86.

Romero, J. (2010): “Construcción residencial y gobierno del territorio en España. De la burbuja inmobiliaria a la recesión", Cuadernos Geográficos de la Universidad de Granada, 47, 17-46. http://revistaseug.ugr.es/index.php/cuadgeo/article/viewFile/600/688

Rullan, O. (2011): "Urbanismo expansivo en el Estado Español: de la utopía a la realidad" en Geografía: retos ambientales y territoriales: conferencias, ponencias, relatorías, mesas redondas del XXII congreso de geógrafos españoles, Universidad de Alicante y Asociación de Geógrafos Españoles, 165-201.

Salom, J., Albertos, J.M., y Fajardo, F. (2015): "Crisis y reestructuración en el Área Metropolitana de Valencia", Revista de estudios andaluces, 32, 1-21. http://institucional.us.es/revistas/andaluces/32/es/A_JULIA\%20SALOM\%20_2015.pdf

Santana, L. M. y Salas, J. (2007): “Análisis de cambios en la ocupación del suelo ocurridos en sabanas de Colombia entre 1987 y 2001, usando imágenes Landsat", GeoFocus, 7, 281-313. http://www.geofocus.org/index.php/geofocus/article/view/121

Solà-Morales, M. (1994): Les formes de creixement urbà. Barcelona: Edicions UPC. 
